ORIGINAL ARTICLE

\title{
Clinical judgment among nursing interns
}

\author{
Azza Fathi Ibrahim*1, Azza Anwar Aly ${ }^{2}$ \\ ${ }^{1}$ Nursing Education Department, Faculty of Nursing, Alexandria University, Egypt \\ ${ }^{2}$ Medical-Surgical Nursing Department, Faculty of Nursing, Damanhur University, Egypt
}

Received: November 26, 2017

Accepted: January 21, 2018

Online Published: January 29, 2018

DOI: $10.5430 /$ cns.v6n3p19

URL: https://doi.org/10.5430/cns.v6n3p19

\begin{abstract}
Clinical judgment (CJ) is considered a vital and crucial ability for nurses that can help them to improve their practical or clinical capabilities, particularly in the internship period. Nursing interns pass through a transient period with significant job responsibilities. They face multifaceted issues, dilemmas, and problems that oblige them to use CJ skills. CJ is a talent and clever skill which should be acquired by nursing interns. The current study is a quantitative study that aims to determine CJ knowledge and skills among nursing interns in nursing practice. A descriptive exploratory design was used. A systematic random sample of 150 nursing interns out of 305 was selected and assigned as a survey group. The data was collected in internship training hospitals in Damanhur, Egypt (Damanhur Medical National Institute, El Raee El Saleh, El Farok and Kafer El Dawar Hospitals). One tool was used for data collection, the Clinical Judgment Evaluation Sheet (CJES), which included two parts. The first part was the Clinical Judgment Knowledge Test that was developed by the researchers to collect the necessary data regarding the CJ knowledge needs of nursing interns. The Lasater Clinical Judgment Rubric (LCJR) 2009 was the second part. It was developed based on Tanner's work in 2006 and included eleven skills in the four phases delineated with CJ developmental skills (noticing, interpreting, responding, and reflecting). Results revealed that the nursing interns have a serious lack of knowledge about the concept of CJ in nursing practice. Additionally, they have a great deficiency in the knowledge about all phases of the CJ process in nursing practice. As well, they suffered from observed insufficiently CJ skills in the nursing practice, respectfully. These findings confirmed that the nursing interns in Damanhur governorate have necessitated to an educational program about CJ knowledge skills. In conclusion, there is an obvious and serious lack of nursing interns' CJ knowledge and skills in nursing practice in Egypt. Therefore, CJ teaching programs or self-learning references are important for them for developing and improving CJ knowledge and skills. Nurse educators and preceptors should take initiative steps in developing teaching sessions, models, and instructional aides to empower their nursing intern's students in CJ practice.
\end{abstract}

Key Words: Clinical judgment, Nursing interns, Knowledge, Skills, Nursing practice

\section{INTRODUCTION}

It is an international and national necessity to improve the quality of nursing services and accordingly decrease the morbidity and mortality rates among patients. Therefore, nurses should recognize their great role in achieving this target. Nursing duties and responsibilities are exposed to multiple problematic situations which require fitting abilities. The practicum in medical, surgical, administration, psy- chiatric, pediatric or obstetric nursing are great sources for competency-based practice with different numbers and types of populations. But, nurses still have limited experiences in decision making, problem-solving and clinical judgment (CJ) capabilities in numerous patient situations. However, there has been much research that considers these capabilities as the backbone of the entire nursing practice. ${ }^{[1-4]} \mathrm{CJ}$ is one of the most crucial cognitive and behavioral abilities which

\footnotetext{
*Correspondence: Azza Fathi Ibrahim; Email: azza_fathy2008@yhoo.com; Address: Nursing Education Department, Faculty of Nursing, Alexandria University, Egypt.
} 
should be a basic nursing talent in the nursing field. Nurses should be prepared to be competent in using $\mathrm{CJ}$, which is the aptitude to observe and perceive, understand, interpret, and to take action and respond to any clinical problem. Thus, CJ is a significant skill in nursing practice and its clinical work, predominantly among nursing interns. ${ }^{[4,5]}$

The first contact where nursing intern students have to face field experience and other real clinical situations is during the internship year. These graduates have to pass one year of clinical training under nursing faculty supervision. It is a difficult transitory educational period where nursing interns confront a lot of new clinical experiences. Accordingly, they should have widespread and inclusive clinical preparation with continuous faculty control and appraisal. Interns become qualified nurses, obtain their bachelor certificate and prepare themselves for employment after passing this field training year. The nursing internship period is considered a traumatic time of changeover among graduate nursing students. They are passing from an atmosphere of theory and academia to one of clinic and practice. Nursing interns continuously acquire directions and instructions from their preceptors without any courses or classes. The preceptors or mentors give the interns guidance and evaluations during their practice. Nursing interns have a large workload thus incurring great stress in carrying out responsibilities. This stress can also be related to being new employees in real work, lacking skills and clinical knowledge, wherein they will be evaluated. $\mathrm{CJ}$ is the most subtle of nursing skills that is very important to be acquired by nursing interns. ${ }^{[5-8]}$

The clinical judgment includes cognitive memorization intellectual processes of data which are mainly required to develop fundamental abilities in healthcare clinical work. It has four basic components. First is experiential knowledge (stem from data recognized by the senses \& noticing). Second is theoretical knowledge (that estimated from linking the objective data with logical rational $\&$ interpretation). The third is applying thought to data (responding appropriately with competence). And fourth is judgment making (accountability with awareness of consequences with a reflection on all work dimensions). Therefore $\mathrm{CJ}$ allows the nurse interns to practice fit clinical decisions in their difficult training period.

\subsection{Significance of the study}

Hence, CJ in clinical nursing practice is a significant educational requirement, particularly in the internship period. Internship period is filled of problems, dilemmas and difficulties in care decision making. Therefore the aim of the current study is to determine the CJ knowledge and skills among nursing interns. This assessment will allow the nurse preceptor and educator to help the nurses' interns to develop competent and valid clinical decisions.

\subsection{Research question}

What are the CJ knowledge and skills among nursing interns students?

\section{MeThOD}

\subsection{Study design}

The study passed through descriptive exploratory design. It was used in the study to explore, identify and determine nursing interns' CJ knowledge and skills in nursing practice.

\subsection{Sample and setting}

The study was conducted at the Faculty of Nursing, University of Damanhur, in Egypt. The data was collected in nursing interns' field experience training hospitals; Damanhur Medical National Institute, El Raee El Saleh, El Farok and Kafer El Dawar Hospitals, in Egypt. The nursing interns were selected from the following hospital departments; Medical, Surgical, Pediatric, Obstetric, Oncology and Kidney Dialysis. The minimum sample size of 130 was calculated and determined by an epidemiological statistical program using the Fishers' formula $\mathrm{z} 2 \mathrm{pq} / \mathrm{d} 2 \mathrm{~A}$. Therefore, a systematic random sample of 150 nursing interns out of 305 was selected from the mentioned settings. The settled eligible criteria were: from both sexes, accepted participation in the study by signing a written informed consent, and have experience in dealing with patient problems.

\subsection{Study tool}

For collecting the necessary data of the current study, the researchers used one tool:

Clinical Judgment Evaluation Sheet (CJES) included two parts:

Part I: Clinical Judgment Knowledge Test. This tool was developed by the researchers to collect the necessary data. It included questions to identify the knowledge needs of nursing interns about clinical judgment regarding concept and importance of CJ and its phases in nursing practice. Questions about socio-demographic data were involved. ${ }^{[3-5]}$

Part II: Lasater Clinical Judgment Rubric (LCJR). This rubric was developed by Kathie Lasater et al., in $2009^{\left[{ }^{[9]}\right.}$ to describe CJ skills developmentally based on Tanner's ${ }^{[4]}$ four phases of $\mathrm{CJ}$ which are noticing, interpreting, responding, and reflecting. Lasater divided each phase into eleven behaviors with four ratings; beginning $=1$, developing $=2$, accomplished $=3$, and exemplary $=4$. The researchers rated student $\mathrm{CJ}$ performance on each of the eleven dimensions of the LCJR. This tool used a quantitative, ordinal numerical 4 Likert scale 
that was filled with observation. The total score of the LCJR is 44 . If the intern obtained less than 15 , this was considered a poor CJ skills score. However, 15 to 29 denoted a good and acceptable level of CJ skills score and above 29 reflected an excellent score.

Part I was developed, and the researchers adopted part II. A pilot study was conducted on 23 nursing interns to test the clarity and applicability of the study tool. This number of students was selected randomly apart from the study sample. According to the pilot results, the tool was modified and prepared for its final draft.

The reliability of the two parts of the instrument was ensured through the use of the Cronbach Alpha Reliability Test which revealed $\alpha>0.7$ internal consistency and a content validity check by a jury of experts in nursing education, medical, surgical and administrative nursing fields.

\subsection{Data collection \& ethical concerns}

The research proposal was submitted to the Faculty of Nursing, Damanhur University, and approval was obtained. Moreover, permission to conduct the study was obtained from the administration of the study above settings, after explaining the purpose of the study. The researchers introduced themselves to the nursing interns and explained the purpose of the study. This was followed by the interns' nurses signing written informed consents on an individual basis. The interns were reassured that when they answered study tool Part I or were observed by using of the CJ rubric in Part II, it would not have any effect on their internship evaluation. As well, they were reassured that their responses would be kept confidential.

\section{The study went through the following procedure}

- Data were collected by the researchers using two methods, that of the structured interview (using Part I of the study tool) and the observation method (using Part II of the study tool) on an individualized basis with each nursing intern.

- The nursing interns were instructed to deal with all clinical situations freely without any tension and instructed to take all care decision as they used to do.

- At the beginning of the interview, the researchers let the nursing intern fill the socio-demographic part and answer the structured questions of Part I of the study tool.

- The nursing interns were left to deal with patient complaints (real clinical situations) in the presence of the researchers who observed the nursing interns' CJ skills (using study tool Part II) on an individual basis. Ex- amples of common clinical situations and problems, which faced the nursing interns were: patient vomiting, bed sores, hyperglycemia, back pain, post-surgical wound care \& pain. Furthermore, urinary catheter problems, headaches, postpartum bleeding, pelvic pain $\&$ congestion, neonate respiratory distress, fever, pediatric diarrhea, dialysis shunt complications, lack of patient knowledge about disease and investigations or drugs side effects, were commonly present in interns practice.

- The CJ skills of the interns led them to take some clinical interventions such as implementing nursing care for pain or vomiting, reporting to the physician or unit management. Using $\mathrm{O}_{2}$ therapy, applying cold or hot compresses, checking glucose levels, administering insulin, seeking urinary tract consultation, conducting health education sessions were other examples of nursing interns clinical decisions.

- Besides observation of student performance, for each CJ phase, the researchers let the nurse intern record his/her achievement. This recording was in terms of: assessment data of the patient problem, scientific base that matched with patient data, meaning behind data, the relationship between data and theoretical interpretation. Moreover, setting priorities, planning for intervention, actual care given, features of communication, ethical consideration, evaluation of care outcome, patient response, self evaluation, and needed data for improvement, were other important data to be reportd by nursing interns (paper $\&$ pens were offered by the researchers for documentation by the interns).

- After observing the achievement of the interns, the researchers collected all intern notes and documents to complete filling of the LCJR.

- All the nurse interns were given the same instructions by the researchers that included all study methodological clarification. They were allotted enough time to do their nursing activities of care or for thinking to take appropriate decisions.

- If the nurse intern confronted only routine work, the researchers left and returned another day to ensure that the nurse intern confronted a problematic clinical situation in which he/she could be observed for CJ skills.

- Each observation session lasted two hours in the nursing interns' morning or evening shifts.

- The researchers used research control approaches to control any extrinsic factors, such as interruptions of procedures, family visit time and student peer conversations. 


\subsection{Data analysis}

The data from the experimental group and the survey group was gathered, prepared, computerized, coded, analyzed and tabulated. Statistical Packages for the Social Sciences (SPSS), Version 20.0 for Windows, and Microsoft Excel Spread Sheet Package (Office 2010) were used for result analysis of the study. Descriptive analysis included the mean, standard deviation, percentage, and frequency.

\section{RESULTS}

\section{Subject profile}

Table 1 clarifies that about two-thirds of participants $(61.33 \%)$ were in their early twenties, and most of them $(77.33 \%)$ were females. As well, the majority of the subjects (74\%) came from rural areas, while about more than one-half of them $(56.66 \%)$ were married. As well, more than one-half of the interns $(29.33 \%, 22 \%)$ had their internship clinical training in Medical and Oncology nursing. As well, about one half of survey group $(22.66 \%, 20 \%)$ had previous work experience time ranging from 5 to 10 months. All of the study subjects $(100 \%)$ were in direct contact with patients. Furthermore, about two-thirds of them (63.33\%) didn't use learning references before.

Table 2 illustrates the nursing interns' knowledge about the concept of $\mathrm{CJ}$ in nursing practice. It is clear that the majority of them $(86.66 \%)$ did not know the meaning of CJ and a very minimal percent $(1.33 \%)$ always used it in nursing practice. More than one-half of the nursing interns (56.66\%) reported that they sometimes recognized that CJ was important in nursing practice. A very minimal percent of the subjects $(2 \%, 10 \%)$ knew the basic skills needed for applying $\mathrm{CJ}$ in nursing practice, as well as only (3.33\%), mentioned an example for CJ in nursing work. Therefore, about twothirds of the participants (64\%) found that they need for prior training regarding CJ. In general, the nursing interns have a serious lack of knowledge about the concept of CJ in nursing practice.

Table 3 shows the interns' knowledge about the phases of the $\mathrm{CJ}$ process in nursing practice. Nearly two-thirds of the subjects $(67.33 \%)$ did not know the meaning of noticing the $\mathrm{CJ}$ process, and at the same time, a very minimal percent $(6.66 \%)$ of them identified some of the components of noticing knowledge needed in the CJ process. Almost all $(89.33 \%)$ of them were not aware of the target of noticing in CJ.

For interpreting, about all nursing (92.66\%) were not aware of the meaning of the interpreting phase in $\mathrm{CJ}$ and negligible percents $(7.33 \%, 3.33 \%)$ of them mentioned a few of the components of interpreting knowledge needed in CJ. Also, almost the participants (94\%) did not identify the target of the interpreting step in CJ.

Table 1. Participant profile as presented by number and percentage

\begin{tabular}{|c|c|c|}
\hline \multirow{2}{*}{ Participants profile } & \multicolumn{2}{|c|}{ Nursing interns $(\mathrm{n}=150)$} \\
\hline & No. & $\%$ \\
\hline \multicolumn{3}{|l|}{ Age } \\
\hline - $22-24$ & 92 & 61.33 \\
\hline - $25-27$ & 58 & 38.66 \\
\hline \multicolumn{3}{|l|}{ Sex } \\
\hline - Male & 34 & 22.66 \\
\hline - Female & 116 & 77.33 \\
\hline \multicolumn{3}{|l|}{ Residence } \\
\hline - Rural & 111 & 74 \\
\hline - Urban & 39 & 26 \\
\hline \multicolumn{3}{|l|}{ Marital status } \\
\hline - Single & 56 & 37.33 \\
\hline - Married & 85 & 56.66 \\
\hline - Divorce & 9 & 6 \\
\hline • Widowed & 0 & 00.0 \\
\hline \multicolumn{3}{|l|}{ Intern specialties } \\
\hline - Medical Nursing & 44 & 29.33 \\
\hline - Surgical Nursing & 13 & 8.66 \\
\hline - Pediatric Nursing & 20 & 13.33 \\
\hline - Obstetric Nursing & 22 & 14.66 \\
\hline - Oncology Nursing & 33 & 22 \\
\hline - Kidney dialysis & 18 & 12 \\
\hline \multicolumn{3}{|l|}{ Intern training duration } \\
\hline - None & 19 & 12.66 \\
\hline - One month & 32 & 21.33 \\
\hline - 2-4 months & 20 & 13.33 \\
\hline - 5-7 months & 34 & 22.66 \\
\hline - 8-10 months & 30 & 20 \\
\hline - 11-12 months & 15 & 10 \\
\hline \multicolumn{3}{|c|}{ Direct interaction with patients } \\
\hline - Yes & 150 & 100.0 \\
\hline - No & 0 & 0.00 \\
\hline \multicolumn{3}{|c|}{ Using self-learning references } \\
\hline - Yes & 55 & 36.66 \\
\hline • No & 95 & 63.33 \\
\hline
\end{tabular}

Contrarily in the responding phase, about two-thirds of the nursing interns $(62.66 \%)$ identify the meaning of the responding step in CJ, but also a very few percent of them $(10 \%, 2 \%)$ reported some of the components of responding knowledge needed in CJ. About only, one-third of the study subjects (30\%) mentioned the target of the responding step in CJ.

Concerning reflecting phase, more than two-thirds of the nursing interns $(77.33 \%)$ did not report the meaning of reflecting in the $\mathrm{CJ}$ process, along with the smallest percent $(6.66 \%, 2.66 \%)$ of them identifying a few of the components 
of reflecting knowledge needed in CJ process. Additionally, the majority of them (74\%) didn't know the target of the reflecting step in CJ.

In the main, it is obvious that the nursing interns have a great deficiency in knowledge about all phases of the $\mathrm{CJ}$ process in nursing practice.

Table 4 describes the CJ skills of the nursing interns in nurs- ing practice by means and standard deviation. According to the LCJR, almost all items that reported by the study subjects, have a mean below two. This result signifies that the total score for CJ skills (noticing, interpreting, responding and reflecting) among nursing interns is below $50 \%$. This result corresponds to observed insufficiently CJ skills among nursing intern in the nursing practice, respectfully.

Table 2. Interns' knowledge about the concept of $\mathrm{CJ}$ in nursing practice as presented by number and percent

\begin{tabular}{|c|c|c|}
\hline \multirow{2}{*}{ Knowledge related to the concept of clinical judgment } & \multicolumn{2}{|c|}{ Nursing interns $(\mathrm{N}=150)$} \\
\hline & No. & $\%$ \\
\hline \multicolumn{3}{|l|}{ Meaning of clinical judgment } \\
\hline - Know & 20 & 13.33 \\
\hline - Didn’t know & 130 & 86.66 \\
\hline \multicolumn{3}{|l|}{ Use clinical judgment in nursing practice } \\
\hline - Always & 2 & 1.33 \\
\hline - Sometimes & 22 & 14.66 \\
\hline - Rarely & 77 & 51.33 \\
\hline - Never & 49 & 32.66 \\
\hline \multicolumn{3}{|l|}{ Clinical judgment in nursing practice is important } \\
\hline - Always & 56 & 37.33 \\
\hline - Sometimes & 85 & 56.66 \\
\hline - Rarely & 9 & 6 \\
\hline - Never & 0 & 00.0 \\
\hline \multicolumn{3}{|l|}{ Nursing basic skills needed to practice clinical judgment ${ }^{*}$} \\
\hline - Careful and accurate observation \& attention & 36 & 24 \\
\hline - Intellectual processing (integrate pieces of empirical \& conceptual information) & 29 & 19.33 \\
\hline - Analysis \& recognition the aspects of a given situation & 18 & 12 \\
\hline - Reasoning \& interpretation & 27 & 18 \\
\hline - Summarizing with conclusion \& logical deduction & 22 & 14.66 \\
\hline - Selection of 2 or 3 answers from the above & 15 & 10 \\
\hline - Selection of all of the above. & 3 & 2 \\
\hline - Mention an example of clinical judgment in nursing & 5 & 3.33 \\
\hline \multicolumn{3}{|l|}{ Prior training is required for clinical judgment } \\
\hline - Yes & 96 & 64 \\
\hline - No & 54 & 36 \\
\hline
\end{tabular}

Note. ${ }^{*}$ Interns allowed to select more than one alternative

\section{Discussion}

Nurses, particularly in a difficult and transitory period like the internship year, should manage multiple and varied client conditions which include many problems and complaints. Moreover, nursing care, good or bad consequences and client progress, are some nursing responsibilities that required them providing justification and explanations in the documentation of nursing interventions. Accordingly, the judgment and decisions of nursing interns are the backbones of total patient care delivery. CJ is supporting and directing interns' care choices for the benefit of the patient, staff, and hospital as a whole. CJ is crucial for nurse interns to acquire remarkable and qualified cognitive and clinical skills for achieving right, credible and valid CJ. ${ }^{[8,10,11]}$
In the current research, the findings clarify that there is a serious lack in knowledge about the concept of CJ in nursing practice and minimum percentages of them knowing the meaning of $\mathrm{CJ}$ and its importance. As well, a negligible number of them were able to identify the benefits and values of CJ in nursing practice. Furthermore, the majority of the nursing interns did not report the basic skills that are needed to practice CJ. Additionally, very little number of the subjects could mention a real example about CJ in nursing. Unfortunately, these results showed inadequate or non existent knowledge about CJ among nurse interns. Accordingly, these findings highlighted the poor effect that this would have on patient care, which is not acceptable in nursing practice and nursing education and nursing field in general. 
Table 3. Interns' knowledge about the phases of $\mathrm{CJ}$ process in nursing practice as presented by number and percent

\begin{tabular}{|c|c|c|}
\hline \multirow{2}{*}{ Knowledge related to clinical judgment phases in nursing practice } & \multicolumn{2}{|c|}{ Nursing interns $(\mathbf{N}=\mathbf{1 5 0})$} \\
\hline & No. & $\%$ \\
\hline \multicolumn{3}{|l|}{ Noticing phase } \\
\hline \multicolumn{3}{|l|}{ Meaning of noticing } \\
\hline - Careful observation of objective and subjective data in clinical patient situation & 49 & 32.66 \\
\hline - Wrong answer & 101 & 67.33 \\
\hline \multicolumn{3}{|l|}{ Components of noticing knowledge needed ${ }^{*}$} \\
\hline - Empirical knowledge (patient situation with subjective and objective data) & 22 & 14.66 \\
\hline - Conceptual knowledge (theoretical basis of the situation) & 75 & 50 \\
\hline - Background \& experience of the nurse & 16 & 10.66 \\
\hline - Nurse's relationship with the patient & 14 & 9.33 \\
\hline - Clinical context of care & 13 & 8.66 \\
\hline - Selection of 2 or 3 answers from the above & 10 & 6.66 \\
\hline - Selection of all of the above & 0 & 0.00 \\
\hline \multicolumn{3}{|l|}{ Nurses' target from noticing } \\
\hline - Recognition patient situation and integrate it with sound scientific theories & 16 & 10.66 \\
\hline - Wrong answer & 134 & 89.33 \\
\hline \multicolumn{3}{|l|}{ Interpreting phase } \\
\hline \multicolumn{3}{|l|}{ Meaning of interpreting } \\
\hline - Assembling data to understand and make sense of it & 11 & 7.33 \\
\hline - Wrong answer & 139 & 92.66 \\
\hline \multicolumn{3}{|l|}{ Components of interpreting knowledge needed ${ }^{*}$} \\
\hline - Particular useful patient data & 33 & 22 \\
\hline - Theoretical data & 45 & 30 \\
\hline - Experiential knowledge & 29 & 19.33 \\
\hline - Mix the three previous data to make sense of it & 33 & 22 \\
\hline - Selection of 2 or 3 answers from the above & 11 & 7.33 \\
\hline - Selection of all of the above & 5 & 3.33 \\
\hline \multicolumn{3}{|l|}{ Nurses' target from interpreting } \\
\hline - Developing a plan for patients' interventions with suitable clinical decisions & 9 & 6 \\
\hline - Wrong answer & 141 & 94 \\
\hline \multicolumn{3}{|l|}{ Responding phase } \\
\hline \multicolumn{3}{|l|}{ Meaning of responding } \\
\hline - The implementation of interventions, derived from patient needs & 94 & 62.66 \\
\hline - Wrong answer & 56 & 37.33 \\
\hline \multicolumn{3}{|l|}{ Components of responding knowledge needed* } \\
\hline - Skills \& procedures knowledge & 15 & 10 \\
\hline - Self-efficacy skills knowledge & 60 & 40 \\
\hline - Anticipated patients responses & 22 & 14.66 \\
\hline - Art of communication and human relations & 13 & 8.66 \\
\hline - Anticipated ethical behaviors & 22 & 14.66 \\
\hline - Selection of 2 or 3 answers from the above & 15 & 10 \\
\hline - Selection of all of the above & 3 & 2 \\
\hline \multicolumn{3}{|l|}{ Nurses' target from responding } \\
\hline - Showing mastery of necessary nursing skills & 45 & 30 \\
\hline - Wrong answer & 105 & 70 \\
\hline \multicolumn{3}{|l|}{ Reflecting phase } \\
\hline \multicolumn{3}{|l|}{ Meaning of reflecting } \\
\hline - Judgment \& learning from experiences in real clinical time while care is occurring & 34 & 22.66 \\
\hline - Didn’t know & 116 & 77.33 \\
\hline \multicolumn{3}{|l|}{ Components of reflecting needed knowledge ${ }^{*}$} \\
\hline - Data of self-evaluation about suitable selection from alternative interventions & 26 & 17.33 \\
\hline - Items of learning transfer availability & 17 & 11.33 \\
\hline - Patient subjective \& objective data after interventions & 32 & 21.33 \\
\hline - Data of plan for improvement & 9 & 6 \\
\hline - Data to involve family and care team in care plan & 8 & 5.33 \\
\hline - Overall implementation effectiveness data & 44 & 29.33 \\
\hline - Selection of 2 or 3 answers from the above & 10 & 6.66 \\
\hline - Selection of all of the above & 4 & 2.66 \\
\hline Nurses' target from reflecting & & \\
\hline - Meeting patient needs and solves his/her problems with high-quality care & 39 & 26 \\
\hline - Wrong answer & 111 & 74 \\
\hline
\end{tabular}

Note. "Interns allowed to select more than one alternatives 
Table 4. Interns' CJ skills in nursing practice as presented by means and standard deviation

\begin{tabular}{lll}
\hline \multirow{2}{*}{ Lasater Clinical Judgment Rubric items } & \multicolumn{2}{c}{ Nursing interns $(\mathbf{N}=\mathbf{1 5 0})$} \\
\cline { 2 - 3 } & Mean & \multicolumn{1}{c}{$\mathbf{S D}$} \\
\hline Noticing & 1.13 & 0.67 \\
- Focusing observation & 1.04 & 0.78 \\
- Recognizing deviations from expected patterns & 2.02 & 0.66 \\
- Information seeking & & \\
Interpreting & 1.34 & 0.83 \\
- Prioritizing data & 2.00 & 0.47 \\
- Making sense of data & & \\
Responding & 1.55 & 0.45 \\
- Calm, confident manner & 1.26 & 0.48 \\
- Clear communication & 1.02 & 0.86 \\
- Well-planned care with flexible intervention & 1.00 & 0.98 \\
- Being skillful & & \\
Reflecting & 1.35 & 0.87 \\
- Evaluation/self-analysis & & 0.57 \\
- Commitment to improvement & & \\
\hline
\end{tabular}

In line with these results, $\mathrm{CJ}$ in nursing is extremely complex which needs a specific sequence of thinking that should be integrated with a specific patient situation. It was preferably used in problematic situations and was characterized by a vague and uncertain hidden process which reflected on health care providers and patients. ${ }^{[2,4]}$ Similar to this view, in the last decade, Yahiro Saylor, in 1994, explained that CJ is a difficult, sophisticated cognitive practice since nurses essentially need earlier and competent preparation to build up its worth in nursing performance. Additionally, in the current century, Nielsen et al., in 2007, emphasized that CJ requires certain traits in a clever nurse to be able to observe and recognize what is beyond this observation with identifying detailed information and then developing logical pertinent associations to reach justifiable reasoning care decisions. Thus, CJ included a series of phases of intellectual, psychological and practical behaviors. ${ }^{[10,11]}$ Furthermore, congruent with the current study results, Simmons et al., 2003, explained that CJ in nursing necessitates a perception of the clinical situation, not related patient problems and illness, but about a holistic view of the patient experiences. Additionally, for resources, attitudes, \& adaptations, CJ may be a difficult process for nurses. ${ }^{[12]}$

In contrary to the present result, much research has reported that the health care professionals have to comprehend the concept of CJ, essentially in the nursing field. Nurses should have unambiguous recognition of $\mathrm{CJ}$ components and phases, which afterward continuously and automatically represents clear interpretation. This manner of thinking fits with under- standable relationships in clinical situations and surrounding circumstances that leads to suitable and valid decisions. ${ }^{[11-13]}$ Also, Van Graan et al., in 2014 and 2016, discussed that professional nurses should have advanced thinking talents of $\mathrm{CJ}$ that are fundamental elements necessary in preparing them in dealing with scientifically progressive technology and more multifaceted nursing roles. Preceptors and clinical instructors are responsible for equipping recently competent nursing graduates with all $\mathrm{CJ}$ knowledge and experiences. Preceptors should before help them to discover sufficient educational chances in this aspect to fulfill the challenges of the nursing profession. ${ }^{[14,15]}$

Nowadays, and for what has been displayed, professional nursing activities are based on the $\mathrm{CJ}$ that is linked to the nursing process cycle. CJ knowledge considers the grassroots for understanding and interpreting patient problems and responding with qualified and competent intervention. $\mathrm{CJ}$ allows nurses to be accountable and believable regarding their nursing responsibilities. Thus, prior preparation for nursing interns regarding $\mathrm{CJ}$ in practice is a must.

Concerning the participants' responses results regarding their knowledge about CJ skills; they prove that they have a great deficiency in knowledge about all phases of the CJ process in nursing practice. The sequential phases of $\mathrm{CJ}$ are integrated into the nursing process and should be inherent in nursing educational preparation if we desire excellence in nursing services. Congruent with this finding, research by Tanner in 2006 and Higuchi et al., in 2002, recommended that the majority of nurses, even professional ones, have an observed deficiency in their awareness and performance regarding the CJ cycle. This situation provides an alarm to tailor all nursing educational experiences with training in critical thinking, problem-solving and decision-making skills which are involved in CJ phases. Besides, nurses should use the built of nursing process model that incorporates $\mathrm{CJ}$ cycle components. If nursing graduates do this, they will overcome the barriers in describing and understanding the phases of $\mathrm{CJ}$ in their practice. ${ }^{[4,16]}$

Dissimilar to current results, the responsibilities of nursing interns have increased more now than in the last era which necessitates that the educational needs of nursing interns should be competent and aware by noticing, interpreting, responding and reflecting as in the phases of the CJ process. Therefore, this shows how those healthcare professionals lack knowledge of such important skills in nursing practice. The consciousness of CJ skills is fundamental for nurses, and the lack of awareness about its phases is considered a huge gap in nursing education. ${ }^{[8,15,16]}$ More or less, nursing interns have a responsibility towards the profession, patients, 
families, and communities in realizing $\mathrm{CJ}$ phases in nursing care.

Through emphasizing the current findings of implementation of CJ skills in interns' practice and by use of the observational Lasater Rubric, it was found that the nursing interns had observed insufficiently CJ skills in nursing practice. Considerably, this issue may be altering the health care system outcome as a whole. Nursing educators and preceptors tend to inherit cognitive, affective and psychomotor skills, more than tendency to teach content. It is very easy to gain subject content, but it is very difficult to acquire the soft and hard skills behind it. Harmonious with the recent result, nursing interns are suffering from finding enough role models and competent teaching staff to teach hidden skills and proper methodology to learn professional skills like critical thinking and CJ skills. Moreover and matching the present finding, Van Graan et al., 2016, clarified that there are a gap and distance in-between theory and practice, particularly in fundamental nursing skills such as CJ both intellectually and practically. Undergraduate nursing students acquire a huge theoretical basis with limited real learning situations in which to conduct their learning transfer. Thus, when they graduate, they suffer from the lack of skills such as CJ skills. ${ }^{[7,14,17]}$

In the same line and since Florence Nightingale's era, many graduate nurses find difficulty in CJ skills implementation. First of all, in the noticing phase, they can't recognize what deviation is behind expected observation, or they may not link or integrate data with previous learning for understanding. As well, the majority of nurses tend to understand assessment data separately. Consequently, graduate nurses may focus on objective and actual patient problems more than subjective and potential complaints. Therefore, interns are confronted with difficulty in the noticing phase. ${ }^{[4,8,18]}$

As well, and matching with previous results, for the interpretation phase in $\mathrm{CJ}$ phases, intern graduates face obstacles in analysis and in building relationships between patient data and theoretical or scientific background which leads to deprived justification and reasoning or poor making sense of data. Thus, they can't prioritize problems and reach conclusions which lead to preparing inappropriate nursing care plans. ${ }^{[7,17,19]}$

Furthermore, in the responding phase and fitting current survey results, most nurses neglect using proper communication skills, both verbal and nonverbal, due to lack of time. Additionally, they ignore focusing on ethical considerations or asking for patient feedback. Interns have several stressors due to great working loads which hinders their communication with family. They have no time to master skills or evaluate their care. ${ }^{[8,9,15]}$ Subjects frequently verbalize that there are many considerations related to family communication, feedback, and ethics that are not considered due to a lack of time besides a lack of skills.

Moreover, and congruent with the poor noticing and interpreting phases, graduate nurses may or may not provide competent care. In the reflecting phase, in Egypt and some other countries, nurses have huge workloads and haven't any time for self or care evaluation. Identification of strengths or weaknesses of care needs time and proper planning which is limited among them. They completely neglect planning for improvement or patient satisfaction. ${ }^{[12,14,17]}$

Incompatible to previous results, Potgieter, in 2012, highlighted that the use of $\mathrm{CJ}$ with its four phases among nurses is an essential issue that helps them to collect, comprehend, relate and analyze patient problems. It is an obligation in a critical job like nursing. CJ allows nurses to provide competent and effective patient care. Nursing graduates should be prepared to think effectively as a normal response to the challenges and changes in the healthcare system. Variety inpatient conditions and the emergence of rare diseases, plus innovative technology in medical devices and communication put commitments on nurses to be CJ users. ${ }^{[13,18,20]}$ Unfortunately, the lack of CJ skills among nursing interns in Egypt represented a big problem rooted in the nursing education system and reflected in ineffective patient outcomes.

\section{Conclusions}

There is an obvious and serious lack in nurse interns' $\mathbf{C J}$ knowledge and skills in nursing practice in Egypt. The nursing interns have a serious lack of knowledge about the concept of $\mathrm{CJ}$ in nursing practice. Additionally, they have a great deficiency in the information about all phases of the $\mathrm{CJ}$ process in nursing practice. As well, they suffered from observed insufficiently CJ skills in the nursing practice, respectfully. These findings confirmed that the nursing interns in Damanhur governorate have necessitated to an educational program about CJ knowledge and skills. In the main, there is an obvious and serious lack of nursing interns' CJ knowledge and skills in nursing practice in Egypt. Therefore, CJ teaching programs or self-learning references are important for them for developing and improving CJ knowledge and skills. Nurse educators and preceptors should take initial steps in developing teaching sessions, models, and instructional aides to empower their nursing intern's students in CJ practice. With the application of these educational approaches among nursing interns, they will be competent decision makers and cleverer professionals in the nursing field which will reflect positively on patient health progress and health care services as a whole. 


\section{Recommendations and further studies}

According to the current study findings, the following recommendations and further studies should be implemented regarding nursing research, nursing education, and nursing practice.

For nursing research:

- Replicate the study for the creative, reflective, discovery and decision-making skills among nursing interns.

- Develop assessment tools for CJ skills.

- Perform a study regarding the relationship between nursing intern CJ skills \& patient outcome.

- Research about nursing intern perceptions regarding CJ skills and internship experience.

For nursing education:

- Integrate CJ knowledge and skills in the nursing curric- ula in Egypt, theoretically and clinically or practically.

- Use different teaching and learning approaches for improving $\mathrm{CJ}$ and decision making skills in undergraduate and graduate clinical training.

For nursing practice:

- Evaluation of CJ skills among registered nurses and patients satisfaction.

- Use self-learning instructional references among nursing interns regarding CJ knowledge and skills.

- Establish a study of training clinical nurse educators, preceptors and registered nurses on using CJ skills in real patient situations.

\section{CONFLICTS OF INTEREST Disclosure}

The authors declare they have no conflicts of interest.

\section{REFERENCES}

[1] Luctkar-Flude M, Baker C, Medves J, et al. Evaluating an interprofessional pediatrics educational module using simulation. Clinical Simulation in Nursing. 2013; 9(5): 163-169. https://doi.org/ $10.1016 / \mathrm{j}$. ecns . 2011.11.008

[2] Gordon JM, Lorilla J, Lehman C. The Role of the Clinical Nurse Specialist in the Future of Health Care in the United States. Perioperative Nursing Clinics. 2012; 343-353. https ://doi .org/10.101 6/j.cpen.2012.06.006

[3] Seacrist M, Noell D. Development of a Tool to Measure Nurse Clinical Judgment during Maternal Mortality Case Review. Journal of Obstetric Gynecologic \& Neonatal Nursing. 2016; 45(6): 870. PMid: 27665070. https://doi.org/10.1016/j.jogn.2016.03.143

[4] Tanner CA. Thinking like a nurse: A research-based model of clinical judgment in nursing. Journal of Nursing Education. 2006; 45: 204-211. PMid: 16780008.

[5] Lasater K. High fidelity simulation and the development of clinical judgment. Journal of Nursing Education. 2007; 46: 269-276. PMid: 17580739 .

[6] Casey K, Fink R, Krugman M, et al. The Graduate Nurse Experience. Journal of Nursing Administration. 2004; 34(6): 303. PMid: 15190226. https://doi.org/10.1097/00005110-200406000 $-00010$

[7] Oermann MH, Garvin MF. Stresses and Challenges for New Graduates in Hospitals. Nurse Education Today. 2002; 22: 225-230. PMid: 12027604. https://doi.org/10.1054/nedt.2001.0695

[8] Kader A, Mohamed EA, Abood SA. Perception of Nurse Interns about Clinical Assignment Preparation Requirements. Journal of American Science. 2012; 8(12): 676-682.

[9] Cato ML, Lasater K, Peeples AI. Nursing students' self-assessment of their simulation experiences. Nursing Education Perspectives. 2009; 30(2): 105-108. PMid: 19476075.
[10] Yahiro K, Saylor A. A critical model for nursing judgment. Journal of Nursing Education. 1994; 33(8): 351-356.

[11] Nielsen A, Stragnell S, Jester P. Guide for reflection using the clinical judgment model. Journal of Nursing Education. 2009; 46: 513-516.

[12] Simmons B, Lanuza D, Fonteyn M, et al. Clinical reasoning in experienced nurses. Western Journal of Nursing Research. 2003; 25: 701-719. PMid: 14528618. https://doi.org/10.1177/019394 5903253092

[13] Black BP. Critical Thinking, the Nursing Process, and Clinical Judgment. Chapter 8. 2008. Available from: https://pdfs.semanticscholar.org/4bc5/06eed955 $71 \mathrm{fd} 129 \mathrm{~d} 36 \mathrm{c} 6 \mathrm{~b} 3 \mathrm{f} 3 \mathrm{c} 887211 \mathrm{c6317}$.pdf

[14] Van Graan A, Williams M, Koen M. Professional nurses' understanding of clinical judgment: A contextual inquiry. Health Sa Gesondheid. 2016; 21: 280-293. https://doi.org/10.1016/j.hsag. 2016. 04.001

[15] Van Graan AC, Koen MP, Williams MJ. Clinical judgment in nursing: A conceptual analysis (Unpublished doctoral thesis). SA: North-West University, Potchefstroom Campus; 2014. 14-66 p.

[16] Higuchi KAS, Donald JG. Thinking processes used by nurses in clinical de decision making. Journal of Nursing Education. 2002; 41: 145-153. PMid: 11954966.

[17] Alfaro-LeFevre R. Critical thinking, clinical reasoning, and clinical judgment: a practical approach (5th Ed.). St. Louis, MO: Saunders Elsevier; 2012.

[18] Potgieter E. Clinical teaching: developing critical thinking in student nurses. Professional Nurse Today. 2012; 16(2): 4-8.

[19] Vitale E. Clinical teaching models for nursing practice: a review of the literature. Professional In fermieristiche. 2015; 67(2): 117-124.

[20] Ashcraft A, Option L. Evaluation of the Lasater Clinical Judgment Rubric. Clinical simulation in nursing. 2009; 5(3): 129-155. https://doi.org/10.1016/j.ecns.2009.04.006 